\title{
Sero - Prevalence of Helicobacter Pylori in HIV Positive Patients and HIV Negative Controls in St. Paul's General Specialized Hospital, Addis Ababa, Ethiopia
}

\author{
Brhanu Teka*, Solomon Gebre - Selassie, Tamrat Abebe \\ Department of Microbiology, Immunology and Parasitology, Addis Ababa University, Addis Ababa, Ethiopia \\ Email address: \\ brhanu.teka@aau.edu.et (T. Brhanu), tamrat.abebe@aau.edu.et (T. Abebe), solomongst@yahoo.com (S. Gebre - Selassie) \\ *Corresponding author
}

\section{To cite this article:}

Brhanu Teka, Solomon Gebre - Selassie, Tamrat Abebe. Sero - Prevalence of Helicobacter Pylori in HIV Positive Patients and HIV Negative Controls in St. Paul's General Specialized Hospital, Addis Ababa, Ethiopia. Science Journal of Public Health.

Vol. 4, No. 5, 2015, pp. 387-393. doi: 10.11648/j.sjph.20160405.14

Received: September 7, 2015; Accepted: September 21, 2015; Published: August 17, 2016

\begin{abstract}
Background. Helicobacter pylori (H. pylori) is recognized as a major human pathogen. Clinical symptoms associated with $H$. pylori infection have been reported in patients with human immunodeficiency virus (HIV). A high, normal, and a lower sero - prevalence of $H$. pylori infection in HIV positive patients than negative controls was found in different studies. The aim of this study was to assess the sero - prevalence of $H$. pylori infection in HIV positive patients and negative controls and determine the impact of CD4 cell count in patients with H. pylori in St. Paul's General Specialized Hospital in Addis Ababa, Ethiopia. Methods. A comparative cross sectional study was conducted in HIV positive patients and controls with gastrointestinal symptoms using Serology test kit $\left(\mathrm{ACON}^{\circledR}\right.$ H. pylori, USA). All individuals who came to Voluntary Counselling and Testing and Anti - Retroviral Therapy to the Out Patient Department of the hospital were examined for complaints of dyspepsia and those with the complaint were tested for H. pylori. Results. Of the 106 HIV positive subjects, 68 $(64.2 \%)$ were positive for anti - H. pylori IgG antibodies; and of the $106 \mathrm{HIV}$ negative controls, 52 (49.1\%) were positive for anti - H. pylori $\mathrm{IgG}$ antibodies $(\mathrm{p}=0.037)$. There was no significant difference of $H$. pylori seroprevalence between relatively higher and lower CD4 cell counts in the HIV positive cases $(\mathrm{p}>0.05)$. Conclusion. A significantly higher seroprevalence of $H$. pylori was demonstrated in the HIV positive subjects. There was no significant difference in the prevalence of $H$. pylori between different CD4+ cell counts in the HIV positive study group.
\end{abstract}

Keywords: Helicobacter Pylori, Sero - Prevalence, HIV, CD4 Count, Dyspepsia

\section{Introduction}

Helicobacter pylori represents one of the most common and medically prominent infections worldwide. Infection with this micro aerobic, gram negative bacterium has been established as an etiologic factor in the development of peptic ulcer disease. In addition, H. pylori infection has been associated firmly with the development of gastric neoplasia, including gastric adenocarcinomas and gastric mucosa associated lymphoid tissue lymphomas [1].

H. pylori is a spiral bacterium with flagellae and a potent producer of urease. It is through the production of bicarbonate, by metabolizing the urea in gastric fluid, that the organism is able to survive in the low $\mathrm{pH}$ environment of the stomach. There it colonizes the gastric epithelial cells passing into the extra - cellular, mucous layer with its more $\mathrm{pH}$ - neutral conditions. There infection induces a host response which results in mucosal damage and a chronic active gastritis. This occurs initially in the non - acid secreting areas of the stomach in the antrum [2]. More than half of all humans are colonized in their stomachs by $H$. pylori. That carriage is nearly universal among adults in developing countries suggests that in earlier times most humans carried these organisms. However, it is not known whether H. pylori has been with all humans for hundreds of years, or for millions of years. In either case, with the changing conditions associated with improved socioeconomic status, $H$. pylori is disappearing in 
industrialized countries and declining in prevalence in some developing countries as well [3].

Infection with $H$. pylori has been recognized as a public health problem worldwide. Previous sero - epidemiologic studies indicated that about $50 \%$ of adults in the developed countries and nearly $90 \%$ of adults in developing countries were sero - positive for $H$. pylori [4].

Recent studies in Ethiopia showed that the overall prevalence of $H$. pylori infection in adult dyspeptic patients, as found by the different diagnostic methods, varied between 69 and $91 \%$ [4].

The risk factors for acquiring H. pylori and HIV infections are different: H. pylori is transmitted by gastro - or fecal oral routes and is associated with low socioeconomic conditions, while HIV is transmitted through sexual intercourse, infected body fluids, and transplacentally [5]. If the host responses to these infections were independent, the prevalence of $H$. pylori should be similar in HIV - infected and non - infected patients. Yet, several epidemiologic studies have generally reported conflicting results while some identifiable patterns can be discerned. It does appear that the incidence of $H$. pylori infection is lower among patients with AIDS compared to matched HIV - infected and - uninfected controls [6].

The bacterium is consistently reported with high prevalence in HIV - negative patients with chronic gastritis and active ulcer disease [7].

Different studies showed that severly immunocompromezed patients with dyspeptic symptoms have much lower prevalence of $H$. pylori and active chronic gastritis in the gastric antrum than in HIV - negative patients $[8,9]$ Furthermore, a substantial but insignificant decrease of $H$. pylori infection prevalence was noted in HIV patients with an extensive decline of CD4 cell count $(<100 / \mu 1)$. [10, 11]. In another studies, the prevalenceof $H$. pylori infection is not significantly different between HIV positive and HIV negative subjects [12].

In our knowledge, there is no study about the prevalence of $H$. pylori in HIV positive patients in Ethiopia and generally not enough in the general population. Therefore the aim of this study was to assess the sero - prevalence of H. pylori infection in HIV positive patients and HIV negative controls with upper gastro intestinal symptoms in St. Paul's General Specialized Hospital, Addis Ababa, Ethiopia.

\section{Materials and Methods}

\subsection{Study Design, Area and Period}

A comparative cross - sectional study was conducted in St. Paul's General Specialized Hospital, Addis Ababa, Ethiopia, during December 2010 and February 2011.

\subsection{Study Population and Sampling Technique}

In the study, those HIV positive patients with dyspepsia and HIV negative subjects with similar symptoms who came to Voluntary Counselling and Testing (VCT) were considered as study population.

\subsection{Sample Size Determination}

The sample size of the study was determined by the following formula:

$$
\mathrm{n} 1=\frac{[\mathrm{Z} \alpha / 2 \sqrt{\mathrm{pq}}(1+1 / \lambda)+\mathrm{Z} \beta \sqrt{\mathrm{p} 1 \mathrm{q} 1}+\mathrm{p} 2 \mathrm{q} 2 / \lambda]^{2}}{\Delta^{2}}
$$

Where $\mathrm{n} 2=\mathrm{n} 1 \lambda, \overline{\mathrm{p}}=(\mathrm{p} 1+\lambda \mathrm{p} 2) /(1+\lambda)$

Where, $\mathrm{p} 1=0.84, \mathrm{p} 2=0.73$, from previous studies (Alimohamed et al, 2002)

$95 \%$ confidence interval and at $80 \%$ power, $\mathrm{n} 1=97, \mathrm{n} 2=97$ and the total minimum sample size calculated is 194 subjects.

\subsection{Eligibility Criteria}

\subsubsection{Inclusion Criteria}

After informed consent, all volunteer HIV sero - positive patients with dyspepsia and HIV negative controls with similar symptoms were included in this study.

\subsubsection{Exclusion Criteria}

Study participants who had received any antibiotic for the treatment of $H$. pylori and/or any other gastro intestinal infection in the previous two weeks were excluded from the study.

\subsection{Data Collection Tools and Procedures}

After informed consent, all volunteer HIV sero - positive patients with dyspepsia and HIV negative controls with similar symptoms were included in this study. First, all individuals who came to the VCT and ART clinics in the OPD of the hospital were examined for complaints of dyspepsia by internist, Public Health Officers and experienced nurses. All individuals with complaints were included in the study and were interviewed to fill the questionnaire. Socio - demographic and other appropriate information were collected using the questionnaire. The major contents of the questionnaire include age group, sex, economic status and previous antibiotic history of the study subjects.

The principal investigator and one assigned laboratory technologist with prior experience were engaged in the laboratory procedures. Two counsellors with prior experience were assigned. Then, after appropriate pre - test counselling and providing information about the study in the VCT centre of the Hospital, the blood which was drawn for the purpose of HIV testing (about $5 \mathrm{ml}$ of venous blood) was used also to test $H$. pylori infection of the individuals for the purpose of this study when they were volunteer to provide their blood for other study other than HIV testing.

Participants who were HIV negative after testing but still dyspeptic were considered as controls and their serum was tested for $H$. pylori.

After the study participants were categorized in to HIV negative and HIV positive, the HIV positive patients were 
again classified depending on their CD4 count from recorded data and then determined the prevalence of $H$. pylori in different CD4 counts.

HIV testing was performed using the national HIV - 1 test algorithm according to the guideline and every information was identified by a code number. For the purpose of this study, serological status of $H$. pylori was tested with commercial $H$. pylori serology test kit (ACON® $H$. PYLORI, USA) following instruction of the manufacturer. The kit was used for the detection of $H$. pylori IgG antibodies in serum and it can detect anti $H$. pylori antibodies with sensitivity (93\%) and specificity (89.2\%). Data quality control was ensured through: Careful selection and training of data collectors, recruiting experienced laboratory personnel and counsellors, Positive and negative controls of serological test kits were checked before the actual sample is tested and Supervision in every step of data collection.

\subsection{Data Entry and Analysis}

Data from the questionnaire and the laboratory test results were entered using SPSS statistical package version 16. Results were summarized by frequency, percentages and means. $\mathrm{X}^{2}$ test was used to compare the prevalence of $H$. pylori between HIV positive and HIV negative groups and HIV positive patients with higher and lower CD4+ counts. $95 \%$ confidence interval was used to measure the strength of association. A value of $\mathrm{P}<0.05$ was regarded as statistically significant.

\subsection{Ethical Considerations}

Ethical approval was obtained from ethical committee of the department of Microbiology, Immunology, and Parasitology of the School of Medicine, Addis Ababa University, before the study. Permission was obtained from the Medical director, Laboratory and ART clinic heads of St. Paul's General Specialized Hospital after explaining the purpose and the procedure of the study.

Pre - and post - test counselling was provided for the study participants. Informed written consent from study subjects was also obtained before sample collection. Information about the study was given to the participants, including purposes and procedures, potential risk and benefits. Identification of the study subject was done only through numerical codes. Patients were treated according to the Helsinki declaration. H. pylori positive patients were treated by clarithromycin - based triple therapy, (Omeprazole $20 \mathrm{mg}$ BID + clarithromycin $500 \mathrm{mg}$ BID + amoxicillin 1 g BID x 10 days).

\section{Results}

The mean age of the study subjects was 33years with the range of 18 - 60 years. Majority of the subjects $(78.3 \%)$ were in the age range of $18-40$ years. Females constituted $64 \%$ of the total study participants. Majority of the participants $(71.7 \%)$ reported that they lived with more than two people in the same house. Only $2.8 \%$ of the study subjects were with monthly income of 1500 to 2499 birr. Among the illiterate participants $(\mathrm{n}=35), 60 \%$ of them were positive for $H$. pylori antibody (Table 1). $79 \%$ (89 of 112) of the total study subjects were unemployed. Of these $52.8 \%$ were H.pylori positive (Table 1). Only 10.7\% (12 of 112) of the study groups were college graduates and the $H$. pylori positivity in this group was $33.3 \%$.

The gender specific prevalence of $H$. pylori infection is the same in the two groups $(56.8 \%$ in males and $56.6 \%$ in females (Table 1).

Table 1. Socio demographic characteristics of study participants in relation to H. pylori serostatus, in St. Paul's Hospital, Addis Ababa, Ethiopia.

\begin{tabular}{|c|c|c|c|}
\hline & & Helicobacter pylori sero & \\
\hline Variable & $\mathbf{N}$ & H. pylori Positive n (\%) & H. pylori Negative n (\%) \\
\hline \multicolumn{4}{|l|}{ Age } \\
\hline$<18$ & 6 & $4(66.7)$ & $2(33.3)$ \\
\hline $18-40$ & 165 & $94(57)$ & $71(43)$ \\
\hline$>40$ & 41 & $23(56.1)$ & $18(43.9)$ \\
\hline \multicolumn{4}{|l|}{ Sex } \\
\hline Male & 74 & $42(56.8)$ & $32(43.2)$ \\
\hline Female & 136 & $77(56.6)$ & $59(43.4)$ \\
\hline \multicolumn{4}{|l|}{ Marital status } \\
\hline Single & 58 & $38(65.5)$ & $20(34.5)$ \\
\hline Married & 107 & $58(54.2)$ & $49(45.8)$ \\
\hline Divorced & 32 & $18(56.2)$ & $14(43.8)$ \\
\hline Widowed & 15 & $7(46.7)$ & $8(53.3)$ \\
\hline \multicolumn{4}{|l|}{ Occupation } \\
\hline Government employed & 22 & $12(54.5)$ & $10(45.5)$ \\
\hline Private employed & 73 & $52(71.2)$ & $21(28.8)$ \\
\hline Unemployed & 89 & $47(52.8)$ & $42(47.2)$ \\
\hline Others & 28 & $10(35.7)$ & $18(64.3)$ \\
\hline \multicolumn{4}{|l|}{ Level of education } \\
\hline Illiterate & 35 & $21(60)$ & $14(40)$ \\
\hline Elementary & 61 & $34(55.7)$ & $27(44.3)$ \\
\hline High school & 104 & $62(59.6)$ & $42(40.4)$ \\
\hline College & 12 & $4(33.3)$ & $8(66.7)$ \\
\hline
\end{tabular}




\begin{tabular}{llll}
\hline & \multicolumn{3}{l}{ Helicobacter pylori sero - status } \\
\hline Variable & N & H. pylori Positive n (\%) & H. pylori Negative n (\%) \\
\hline Monthly income & & & \\
No income & 18 & $10(55.6)$ & $8(44.4)$ \\
Less than 500 birr & 99 & $54(54.5)$ & $45(45.5)$ \\
500 to 1499 birr & 85 & $53(62.4)$ & $32(37.6)$ \\
1500 to 2499 & 6 & $2(33.3)$ & $4(66.7)$ \\
No of people living together & & & $10(71.4)$ \\
None & 14 & $4(28.6)$ & $8(40)$ \\
One & 20 & $12(60)$ & $12(46.2)$ \\
Two & 26 & $14(53.8)$ & $61(40.1)$ \\
\hline two & 152 & $91(59.9)$ & \\
\hline
\end{tabular}

Table 2. Demographic data in HIV positive and HIV negative study groups, St Paul's Hospital, Addis Ababa.

\begin{tabular}{lll}
\hline & HIV positive (n=106) (\%) & HIV negative (106) n (\%) \\
\hline Age (years) [range] & $\mathbf{1 8 - 5 5}$ & $\mathbf{1 8 - 6 0}$ \\
\hline Sex & & \\
Male & $32(30.8)$ & $42(39.6)$ \\
Female & $72(69.2)$ & $64(60.4)$ \\
Marital status & & \\
Single & $24(22.6)$ & $34(32.1)$ \\
Married & $60(56.6)$ & $47(44.3)$ \\
Divorced & $14(13.2)$ & $18(17)$ \\
Widowed & $8(7.5)$ & $7(6.6)$ \\
Occupation & & \\
Government employed & $16(15.1)$ & $6(5.7)$ \\
Private employed & $42(39.6)$ & $31(29.2)$ \\
Unemployed & $42(39.6)$ & $47(44.3)$ \\
Others & $6(5.7)$ & $22(20.8)$ \\
Level of Education & & \\
Illiterate & $16(15.1)$ & $19(17.9)$ \\
Elementary school & $30(28.3)$ & $31(29.2)$ \\
High school & $56(52.8)$ & $48(45.3)$ \\
College & $4(3.8)$ & $8(7.5)$ \\
No of people living together & & \\
None & $4(3.8)$ & $10(9.4)$ \\
One & $2(1.9)$ & $18(17)$ \\
Two & $20(18.9)$ & $6(5.7)$ \\
More than two & $80(75.5)$ & $72(67.9)$ \\
\hline
\end{tabular}

\section{HIV Versus H.pylori infection}

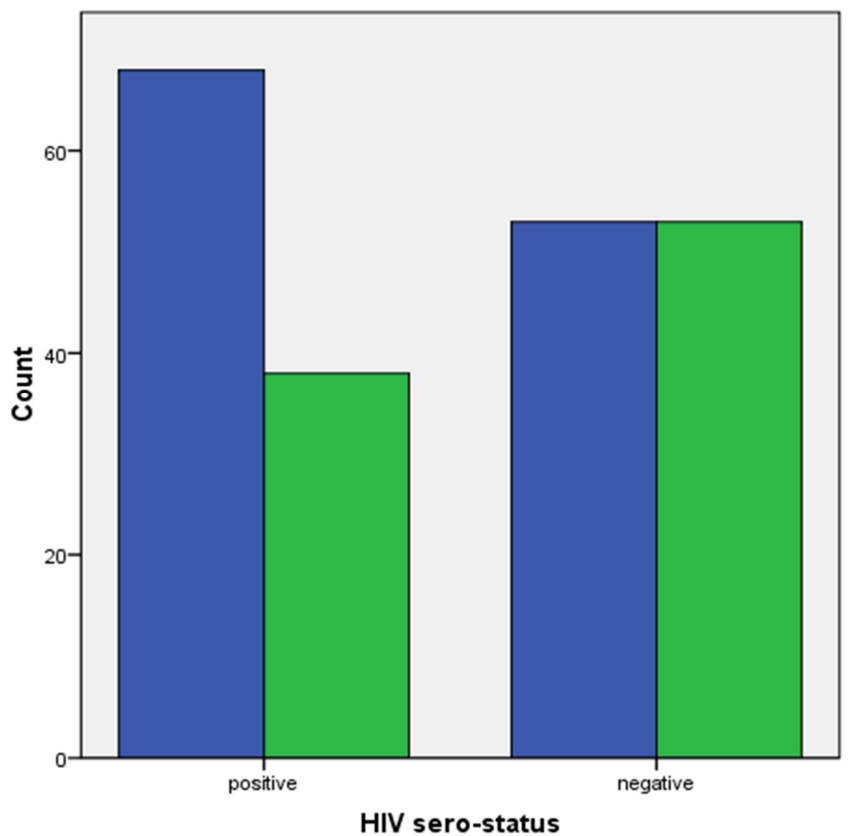

HIV sero-status
H.pylori serostatus

H.pylori positive

H.pylori negative

Figure 1. H. pylori serostatus in HIV - infected and uninfected individuals, St. Paul's Hospital, Addis Ababa, Ethiopia. 
The overall prevalence of $H$. pylori infection in this study population was $57.08 \%(120 / 212)$

The mean age of the HIV - positive group was 34 years (range $18-55$ versus $18-60$ ) which was not statistically different from that of HIV - negative group. There were less male patients in the HIV positive group than in the HIV negative group (30\% versus39.6\%) (Table 2). Regarding marital status $56.6 \%$ of the HIV positive group was married while $44.3 \%$ were married in the HIV negative group. Government employed subjects were more in the HIV positive group than in the HIV negative group $(15.1 \%, 5.7 \%$ respectively) (Table 2).

The prevalence of $H$. pylori infection in HIV negative group is significantly lower than in the HIV positive group. (68/106; 64.2\% Vs 52/106; 49.1\%, P= 0.037) (Table 3). Sixty eight of the $106(64.2 \%)$ HIV positive subjects were $H$. pylori positive while fifty two of the 106 (49.1\%) HIV negative were positive for $H$. pylori.

The HIV positive patients was further sub classified in to two groups according to their CD4+ lymphocyte count $\left(\right.$ mean $=393.57 / \mathrm{mm}^{3} ;$ median $=406 / \mathrm{mm}^{3}$ and range $\left.=693 / \mathrm{mm}^{3}\right)$.

Among the HIV positive patients there was no significant difference in the prevalence of $H$. pylori infection between CD4+ count less than 200 cells/ $\mu 1$ and CD4+ count greater than 200 cells/ $\mu$ l. $(\mathrm{p}=0.493)$ (Table 4).

Table 3. The relationship between Helicobacter pylori infection and HIV infection, St Paul's Hospital, Addis Ababa, Ethiopia.

\begin{tabular}{llll}
\hline & HIV positive $(\mathbf{n = 1 0 6}) \mathbf{\%}$ & HIV Negative $(\mathbf{n = 1 0 6})$ \% & P - value \\
\hline HP positive & $68(64.2)$ & $52(49.1)$ & 0.037 \\
HP Negative & $38(35.8)$ & $54(50.9)$ & \\
\hline
\end{tabular}

Table 4. H. pylori infection and CD4+ count in HIV positive patients.

\begin{tabular}{lllll}
\hline & & \multicolumn{2}{l}{ H. pylori sero-status } & \\
\cline { 3 - 5 } & & Positive & Negative & P-value \\
\hline \multirow{2}{*}{ CD4 $^{+}$count } & $\mathrm{CD}^{+} \leq 200 / \mu 1(\mathrm{n}=38)$ & $26(68.4 \%)$ & $12(31.6 \%)$ & \multirow{2}{*}{0.493} \\
\hline
\end{tabular}

\section{Discussion}

The aim of this study was to assess the sero - prevalence of Helicobacter pylori infection in HIV positive patients and HIV negative controls with dyspepsia and determine the impact of CD4 cell count in patients with $H$. pylori infection in St. Paul's General Specialized Hospital in Addis Ababa.

In the present study, it is found that the overall prevalence of $H$. pylori infection was $57 \%$. This result is in agreement with previous studies which showed that the prevalence of $H$. pylori in dyspeptic patients was approximately $50 \%$ [13] in the general population. But it also contradicted with some studies in the developing countries which showed high prevalence up to $90 \%$ [4]. This disagreement might be due to use of different methods for the diagnosis of H.pylori between the present study and the previous studies.

This study aimed to see if any difference was found in the sero - prevalence $H$. pylori between HIV positive patients and HIV negative controls.

The prevalence of anti - H. pylori IgG antibody in HIV positive patients in this study was significantly higher $(\mathrm{p}<$ $0.05)$ than that in the HIV negative control group $(64.2 \% \mathrm{Vs}$ 49.1\%). Thus, it is indicated that HIV positive patients and HIV negative individuals have different susceptibility for the colonization H.pylori in gut. This contradicts with different previous studies in overseas $[10,11,14,15]$ that showed lower prevalence of $H$. pylori infection in HIV positive patients as compared to HIV negative controls. The reasons for such lower prevalence might be due to lack of CD4 cells, use of antibiotics and proton pump inhibitors and competitive inhibition by other pathogens. According to these studies $\mathrm{CD}^{+}$lymphocytes were involved in the pathogenesis of $H$. pylori related gastritis and this gastritis might be a mechanism by which $H$. pylori colonization is enhanced. Therefore, fully functional $\mathrm{CD}^{+}$lymphocytes might be required for $H$. pylori infection and $H$. pylori related peptic ulcer disease. However, our finding was in agreement with some previous studies [6]. The reason of higher prevalence of $H$. pylori in the HIV positive group in this study may be due to (i) hypochlorhydria sometimes associated with HIV infection.

Therefore the increased prevalence of $H$. pylori in HIV positive group of this study as compared to the HIV negative control group could be due to hypergammaglobulinemia since the sole diagnostic tool in this study was serological test to determine anti - H. pylori IgG. This may be due the fact that most HIV infected patients had IgG antibodies against other frequently encountered pathogens. (iii) Cell mediated immune deficiency in the HIV positive patients may also contribute to the high prevalence of $H$. pylori infection in this group. It is reported that Th1 and Th2 cells appear to predominantly present in the gastric mucosa of $H$. pylori positive subjects. Hence Th1 and Th2 cells play a central role in the immune regulation during $H$. pylori infection [17]. In HIV positive patients, there is a depletion of $\mathrm{T}$ helper cells and this may create favourable condition for the colonization and pathogenesis of H.pylori in the HIV positive group.

(iv)The mucosal surface of the gastro intestinal tract serves as a predominant structural and immunological barrier against microorganisms [17]. Thus, loss of the integrity of the mucosal surface such as, disruption of the tight epithelial 
junctions may be the possible explanation for the high prevalence of $H$. pylori infection in HIV positive patients than in HIV negative controls in the present study.

In our study, the HIV positive patients were sub classified in to two groups based on their $\mathrm{CD} 4^{+}$lymphocyte count to analyse the difference in sero - prevalence of $H$. pylori between the two groups. This sub analysis showed that no significant difference $(\mathrm{p}=0.493)$ in the prevalence of H. pylori infection in the two groups $\left(\mathrm{CD}^{+}<200 / \mu 1\right.$ and $\left.\mathrm{CD}^{+}>200 / \mu 1\right)$. This result may be limited by the small number of subjects in each group. The result of this study on the impact of CD4 cell count in the prevalence of $H$. pylori infection in HIV positive patients was agreed with other previous studies in Italy and Greek [9, 11, 18]. Our study and the previous studies showed insignificant difference of $H$. pylori infection between low $\left(\mathrm{CD}^{+}<\right.$ $200 / \mu \mathrm{l})$ and high $\left(\mathrm{CD}^{+}>200 / \mu \mathrm{l}\right) \mathrm{CD} 4$ cell counts. But this study was against studies conducted in Kenya, China and Brazil $(12,15,19)$ which showed the prevalence of $H$. pylori was less in $\mathrm{CD}^{+}$cell count less than $200 / \mu \mathrm{l}$ as compared to the prevalence of $H$. pylori in patients with CD4 cell count greater than $200 / \mu 1$.

The low prevalence of $H$. pylori in patients with $\mathrm{CD}^{+}$cell count less than $200 / \mu 1$ in the previous studies might be due to: in HIV positive patients with advanced AIDS stage, the frequent exposure to antimicrobials or histamine - 2 receptor antagonists may reduce $H$. pylori infection. But most of the HIV positive subjects in this study were not with advanced AIDS with mean CD4 count of $393.57 / \mathrm{mm}^{3}$ and relatively free of frequent use of different antibiotics. Therefore according to results of this study decrease in absolute CD $4^{+}$ lymphocytes itself may not correlate with reduced $H$. pylori infection but may be due to the frequent exposure to antibiotics in HIV patients with advanced AIDS. This needs further study by considering the different clinical stages of AIDS.

\section{Conclusions and Recommendations}

From this study it is demonstrated that a higher prevalence of $H$. pylori infection in HIV sero positive patients than HIV negative control group with similar upper gastro intestinal symptoms. The HIV positive group showed a statistically significant higher sero - prevalence of H. pylori as compared to the HIV negative control group. Hypochlorhydria and depressed mucosal immune function may lead HIV positive patients to $H$. pylori colonization in the gut. It is also revealed insignificant difference of $H$. pylori prevalence in HIV positive patients with higher and lower CD4+ lymphocyte counts.

Based on our study the following recommendations were given.

- Consideration should be given for diagnostic evaluation of $H$. pylori in HIV patients.

- Large and well - designed studies must be conducted to determine the association between decreased acid secretion and $H$. pylori colonization in the gut.
- Researchers in future studies should control the potential confounder of antibiotic treatment in HIV positive patients beyond two week exclusion period.

\section{Acknowledgments}

My deepest heartfelt thanks go to my advisors, Dr. Solomon Gebre - Selassie and Dr. Tamrat Abebe, for providing me support and constructive comments during the write - up of this thesis project paper. I would also like to thank my friends and family for sharing their invaluable ideas and material support.

Finally, I would like to thank all the patients, their caretakers, the data collectors and the laboratory technologists who participated in this study

\section{References}

[1] Versalovic J. (2003). Helicobacter pylori Pathology and Diagnostic Strategies. Am. J Clin Pathol.119: 403-412.

[2] Ostrow B. (2010). Peptic Ulcer Disease-the impact of Helicobacter pylori on management in the developing world. Surgery in Africa Monthly Review. http: //www.ptolemy.ca/members/archives/2007/ulcer/index.htm (Accessed on 28AUG2010).

[3] Blaser MJ. and Berg DE. (2001). Helicobacter pylori genetic diversity and risk of human disease. Journal of Clinical Investigation. 107 (7): 767-773.

[4] Tadege T., Mengistu Y., Desta K., Asrat D. (2005). Seroprevalence of Helicobacter pylori Infection in and its Relationship with ABO Blood Groups. Ethiop.J. Health Dev. 19 (1): 55-59.

[5] Daniel T. Nevin, Christopher J. Morgan, David Y. Graham, Robert M. Genta. (2014). Helicobacter pylori Gastritis in HIV-Infected Patients: A Review. Helicobacter 19: 323-329.

[6] Romanelli F., Smith KM. and Murphy B. S. (2007). Does HIV Infection Alter the Incidence or Pathology of Helicobacter pylori Infection? AIDS patient care and STDs. 21 (12): 90819.

[7] Marano BJ Jr., Smith F. and Bonauno C. A. (1993). Helicobacter pylori prevalence in acquired immunodeficiency syndrome. Am.J.Gastroenterology. 88: 687-690.

[8] Mach T, Skwara P, Biesiada G, Cieśla A, Macura A. (2007). Morphological changes of the upper gastrointestinal tract mucosa and Helicobacter pylori infection in HIV-positive patients with severe immunodeficiency and symptoms of dyspepsia. Med Sci Monit. 13 (1): CR14-9).

[9] Lichterfeld M., Lorenz C., Nischalke H D., Scheurlen Ch., Sauerbruch T., Rockstroh J K. (2002). Decreased Prevalence of Helicobacter pylori Infection in HIV Patients with AIDS defining Diseases. Z Gastroenterol. 40 (1): 11-14.

[10] Panos GZ., Xirouchakis E., Tzias V., Charatsis G., Bliziotis IA., Doulgeroglou V., Margetis N., Falagas ME. (2007). Helicobacter pylori infection in symptomatic HIVseropositive and seronegative patients: a case-control study. AIDS Res Hum Retroviruses. 23 (5): 709-12. 
[11] Fabris P., Pilotto A., Bozzolaà L., Tositti G., Soffiati G., Manfrin V., De Lalla F. (2002). Serum pepsinogen and gastrin levels in HIV-positive patients: relationship with CD4+ cell count and Helicobacter pylori infection. Aliment Pharmacol Ther.16: 807-811.

[12] Alimohamed F., Lule N., Nyong'o A., Bwayo J; Rana FS. (2002). Prevalence of Helicobacter pylori and endoscopic findings in HIV seropositive patients with upper gastrointestinal tract symptoms at Kenyatta National Hospital, Nairobi. East African Medical journal. 79: 5, 226-231.

[13] Nielsen H., Andersen LP. (2009). Sero-diagnosis of Helicobacter pylori infection in patients with human immunodeficiency virus infection. APMIS. 103, 7-8: 689-692.

[14] Francis N D., Logan R P H., Walker MM., Polson RJ., Boylston A W., Pinching A J., Harris J R W., Baron J H. (1990). Campylobacter pylori in the upper gastrointestinal tract of patients with HIV-1 infection. J Clin Pathol. 43: 6062 .

[15] Luo HB., Hu ZW., Guo JW., (2009). Helicobacter pylori infection in the gastric mucosa of patients with HIV/AIDS in different clinical stages. Journal of southern medical university. 29 (7): 1397-9.

[16] Brenchley JM. and Douek DC (2008). HIV infection and the gastrointestinal immune system. Mucosal Immunol.1: 23-30.

[17] Abbott TC. Prevalence of Helicobacter pylori and its relation to cytotoxin-associated gene A status in HIV positive and negative haematology patients. http://etd.uovs.ac.za/ETDdb//theses/available/etd-09042009-

110536/unrestricted/AbbottTC.pdf (2007) (accessedon 4SEP2010).

[18] Lionetti P., Amarri S., Silenzi F., Galli L., Cellini M., de Martino M., Vierucci A. (1999). Prevalence of Helicobacter pylori Infection Detected by Serology and 13C-Urea Breath Test in HIV-1 Perinatally Infected Children. Journal of Pediatric Gastroenterology \& Nutrition. 28 (3): 301-306.

[19] Boyle (2001). GI and Hepatic Diseases Associated with HIV: HIV-Infected Patients Have a High Rate of $H$. pylori Infection. AIDS Read, 11 (7): 354-5, 359-61, 363. 